\title{
27. GLOMAR CHALLENGER DRILLINGS: THE MAGNETIC FIELD PRODUCED BY THE DRILL AND DRILL STRING
}

\author{
Nikolai Petersen, Institut f. Allg. u. Angew. Geophysik, Ludwig-Maximilians-Universität, Theresienstr. 41, Munich
}

By analyzing the natural remanent magnetization of Leg 37 and Leg 45 basement rocks, it was noticed that many rocks possess complex magnetizations (J. Hall, Initial Report, DSDP Leg 37; P. Johnson, Initial Report DSDP, Leg 45). These magnetizations often consist of superpositions of two different magnetization components, the original thermoremanent magnetization and a relatively unstable component in the direction of the drill axis. The latter one can normally be erased by stepwise alternating field demagnetization. Hall and Johnson have interpreted this magnetization component as being induced by the drilling process and, therefore, have called it "drilling remanence."

It has been argued that relatively strong magnetic fields produced by the drill and drill string, acting on the rocks during the drilling process, might be the cause of the drilling remanence.

In an attempt to clarify this question, the axial $\Delta \mathrm{Z}$-component of the magnetic field inside and outside of the drill and drill string has been measured with a Bell-Gaussmeter. The results of the measurements are shown in Figure 1. The magnetic field produced by the drill bit is small, not exceeding $1 \mathrm{Oe}$; drill collar and bumper sub produce stronger magnetic fields with a maximum of about
5 Oe. This means that the additional magnetic field at the actual spot of drilling is small. It also seems that the 5-Oe magnetic field in the sub and drill collar are not sufficient to produce an isothermal remanent magnetization of the order of magnitude of the observed drilling remanence. Therefore, the drilling remanence is more likely to be a "piezo" remanent magnetization that is built up by the considerable pressure that is acting on the drilled rock due to the weight of the drill string.

Finally, not to give the wrong impression, the observed drilling remanence does not seem to impose a serious problem to the paleomagnetic analysis, as it can selectively be erased by alternating field demagnetization.

\section{REFERENCES}

Hall, J.M., and Ryall, P.J.C., 1977. Paleomagnetism of basement rocks, Leg 37. In Aumento, F., Melson, W.G., et al. Initial Reports of the Deep Sea Drilling Project, v.37: Washington (U.S. Government Printing Office), p. 423-424.

Johnson, P., 1978. Paleomagnetism of rock samples. In Melson, W.G., Rabinowitz, P.D., et al., Initial Reports of the Deep Sea Drilling Project, v.45: Washington (U.S. Government Printing Office). 
A

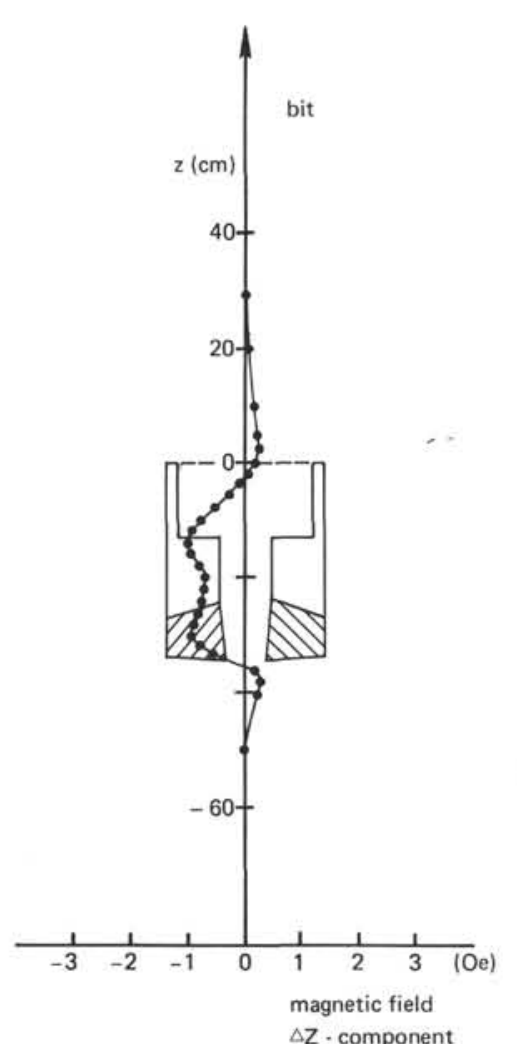

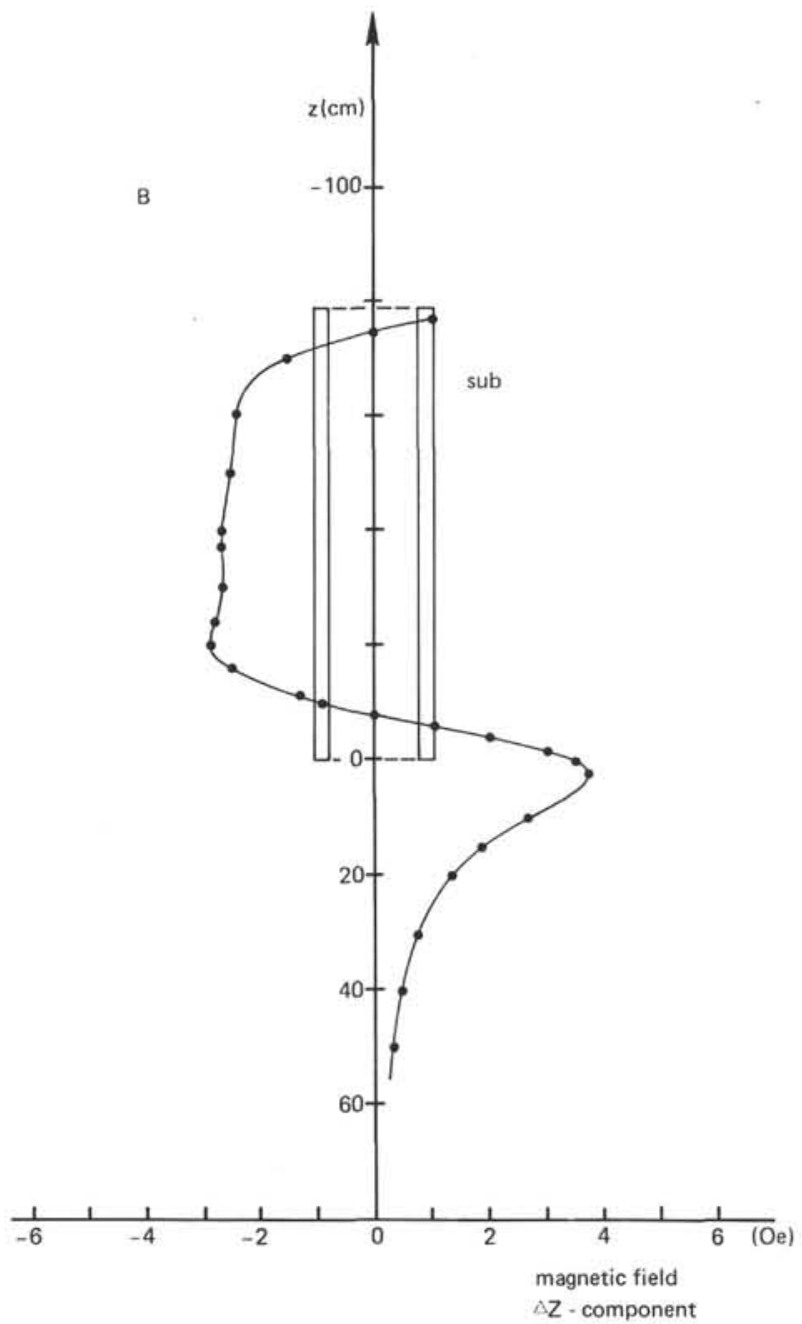

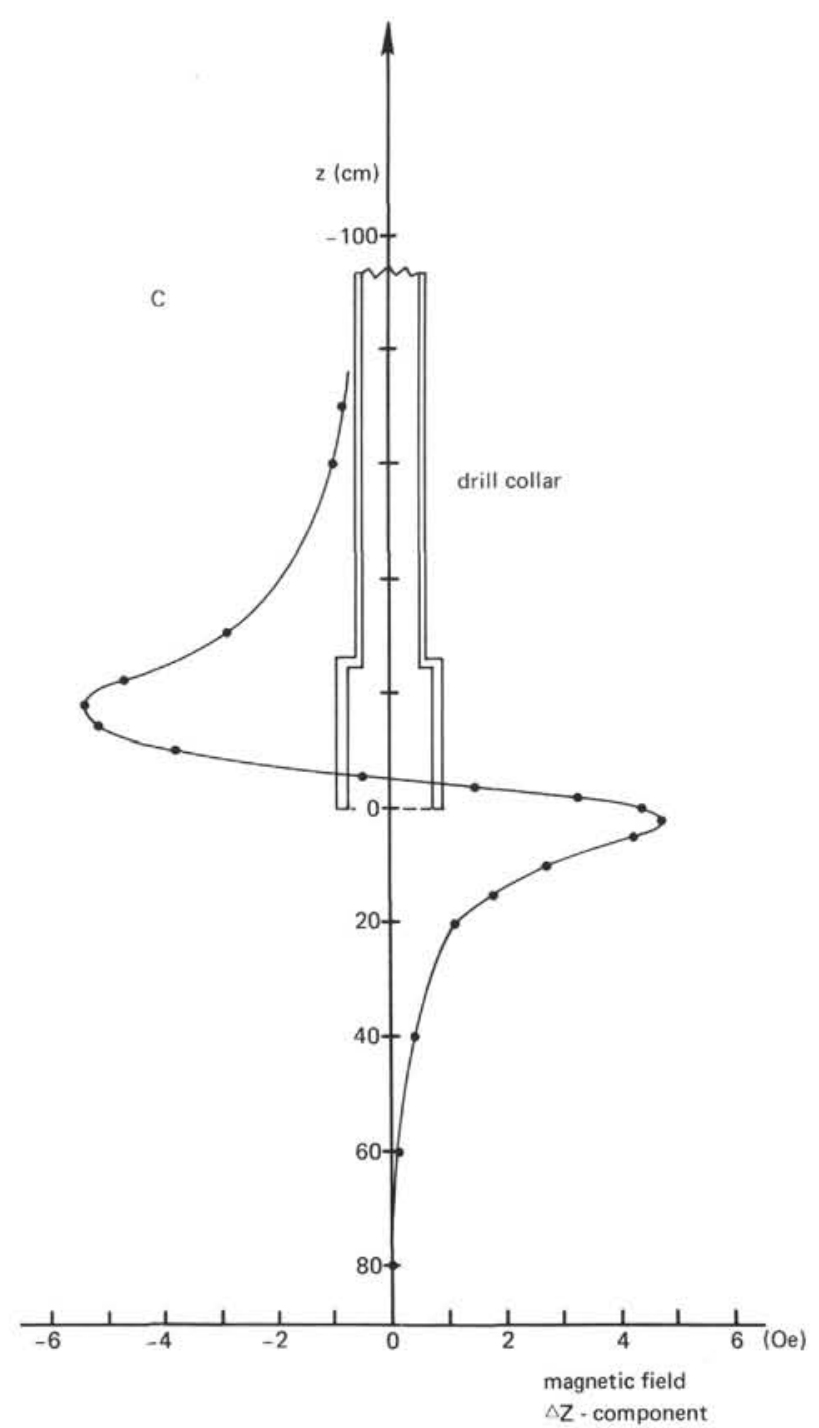

Figure 1. Results of magnetic field measurements inside and outside the drill and drill string from Leg 46 drill bit CA-767. 